\title{
SÍNTESE DE FOTOPROTETORES E SUA IMOBILIZAÇÃO EM POLI(METACRILATO DE METILO): UM PROJETO INTEGRADO DE QUÍMICA ORGÂNICA, QUÍMICA DE POLÍMEROS E FOTOQUÍMICA
}

\author{
Dina Maria B. Murtinho*, Maria Elisa S. Serra e Marta Pineiro \\ Departamento de Química, Faculdade de Ciências e Tecnologia, Universidade de Coimbra, 3004-535 Coimbra - Portugal
}

Recebido em 18/11/09; aceito em 7/5/10; publicado na web em 24/8/10

\begin{abstract}
SUNSCREEN SYNTHESIS AND THEIR IMMOBILISITION ON POLYMETHYLMETHACRYLATE: AN INTEGRATED PROJECT IN ORGANIC CHEMISTRY, POLYMER CHEMISTRY AND PHOTOCHEMISTRY. Dibenzalacetone and other aldol condensation products are known sunscreens commonly used in cosmetics. This type of compounds can easily be prepared in an Organic Chemistry Lab by reaction of aldehydes with ketones in basic medium. These compounds can be incorporated in poly(methyl methacrylate) and used as UV light absorbers, for example in sunglasses. This project has the advantage of using inexpensive reagents which are readily available in Chemistry Laboratories. This experiment can also be a base starting point for discussions of organic, polymer and photochemistry topics.
\end{abstract}

Keywords: aldol condensation; poly(methyl methacrylate); chemical UV-light absorbers

\section{INTRODUÇÃO}

Este projeto pretende integrar num só trabalho experimental conhecimentos de diferentes áreas da Química. A investigação em Química é cada vez mais interdisciplinar, pelo que os alunos universitários devem ser familiarizados com a interpenetração dos vários domínios da ciência de forma a poderem responder aos desafios da investigação atual. Assim, propõe-se a realização de um projeto com uma componente de síntese orgânica, uma componente de química de polímeros (através da síntese e caracterização de um polímero) e outra fotoquímica, que envolve a aplicação dos produtos como potenciais fotoprotetores. Foi publicado em 1999 um trabalho envolvendo a preparação de um polímero com capacidade de absorver radiação do ultravioleta (UV). ${ }^{1}$ No entanto, verificámos que este apresenta apenas uma vertente mais orientada para a síntese orgânica e que o fotoprotetor utilizado faz uso de reagentes mais caros e portanto menos acessíveis a alguns laboratórios de aulas. O presente trabalho constitui uma boa alternativa, uma vez que envolve a utilização de reagentes comuns e é um projeto mais interdisciplinar.

A radiação do UV apresenta efeitos adversos no nosso organismo sendo a principal causa de câncer de pele. Estudos apresentados por organizações internacionais, entre eles a OMS (Organização Mundial de Saúde) relacionam graves problemas de saúde ocular, tal como pterígio, ceratose aquitinica ou alterações tumorais nos olhos, com a exposição solar excessiva, sobretudo em países tropicais como é o caso do Brasil. Suspeita-se também que a radiação do UV possa ser um dos causadores de cataratas e do envelhecimento da pele. Muitos produtos como os protectores solares e os óculos contêm compostos que protegem da radiação UV.

Ainda não existe uma norma mundial ISO que regulamente as características obrigatórias para os óculos de sol, mas a crescente preocupação com a influência da radiação solar na saúde ocular tem levado à publicação de normas europeias (EN 1836:2005), australianas (AS/NZ1067:2003), americanas (ANSI Z80.3-2001) e brasileiras (ABNT NBR 15.111:2004). Estas normas, de carácter obrigatório para a comercialização de óculos de sol, referem no Art. $1^{\circ}$ do Projeto de Lei No 5534 de 2005 do Senado Federal que: "Os óculos de sol comercializados no país devem, obrigatoriamente, oferecer protecção contra a radiação ultravioleta e seguir as demais

*e-mail: dmurtinho@ci.uc.pt especificações previstas em normas da ABNT".

Definem-se três categorias de radiação de UV: UVA (320-400 $\mathrm{nm})$ e UVB (290-320 nm) e UVC (100-280 nm). Os UVC, os mais perigosos, são bloqueados pelo ozono e chegam pouco à superfície terrestre. Os UVB são cerca de 1000 vezes mais potentes que os UVA, pelo que também apresentam elevada perigosidade. ${ }^{2,3}$

Os fotoprotetores são compostos que exibem um efeito protector em relação aos raios solares. ${ }^{4}$ Estes podem ser divididos em duas categorias principais: os "físicos" que reflectem a luz solar, actuando como uma barreira mecânica (de que são exemplo o dióxido de titânio ou o óxido de zinco) e os "químicos" que absorvem selectivamente a radiação do ultravioleta e permitem a transmissão da luz visível (como os $p$-aminobenzoatos, PABA, e os derivados da benzofenona). ${ }^{4}$ Neste projeto foram preparados três produtos de condensação aldólica, como a dibenzilidenoacetona (um conhecido fotoprotetor ${ }^{5}$ ) que após incorporação em poli(metacrilato de metilo) foram testados quanto à sua eficácia na absorção de radiação UV e classificados segundo as categorias de óculos de sol e limites de transmitância.

\section{RESULTADOS E DISCUSSÃO}

Este projeto pode ser efectuado em cerca de três ou quatro períodos experimentais, iniciando-se com a síntese dos produtos de condensação aldólica, seguido da preparação do polímero num segundo período experimental e no terceiro proceder-se-á à preparação de filmes de poli(metacrilato de metilo) com e sem fotoprotetores imobilizados. Caso se pretenda efectuar um trabalho um pouco mais completo pode reservar-se um quarto período para a determinação do peso molecular médio do polímero preparado.

A condensação aldólica consiste na reacção de um ião enolato de um composto carbonílico, aldeído ou cetona, com outra molécula de composto carbonílico, que pode ou não ser igual à primeira. Se se utilizar mais do que um composto com átomos de hidrogénio enolizáveis $\left(\mathrm{H}_{\alpha}\right)$ pode formar-se uma mistura de produtos de condensação. Assim, para favorecer a formação de um único produto, utiliza-se um composto carbonílico que não possui hidrogénios enolizáveis e outro composto carbonílico que os possui. Nestas condições o produto de condensação é uma $\alpha$-hidroxicetona ou um $\alpha$-hidroxialdeído, que sofre desidratação, dando origem a uma cetona ou aldeído $\alpha, \beta$-insaturado. Se este produto ainda possuir $\mathrm{H}_{\alpha}$ pode ocorrer nova condensação com outra molécula de composto carbo- 
nílico. Neste projeto foram preparados três produtos de condensação aldólica cruzada, utilizando acetona, e três aldeídos, o benzaldeído, o anisaldeído ( $p$-metoxibenzaldeído) e o cinamaldeído (Esquema 1).

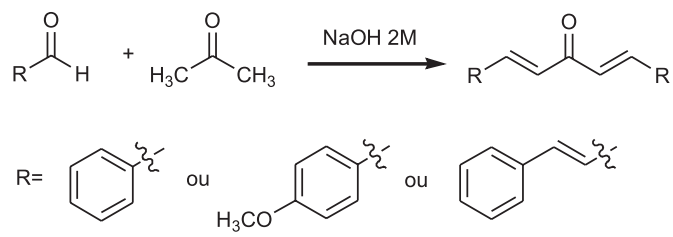

Mecanismo da reacção de condensação aldólica

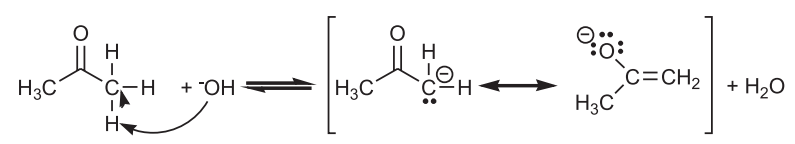<smiles>[R]C(O)CC(C)=O</smiles><smiles>[R]C=CC(C)=O</smiles>

Esquema 1.

A reacção é efectuada em meio básico, utilizando etanol como solvente e os produtos cristalizam facilmente do meio reaccional por arrefecimento em gelo. Caso seja necessária purificação adicional os compostos podem ser recristalizados em etanol a quente.

O poli(metacrilato de metilo), PMMA, é um polímero altamente transparente sendo utilizado como substituto do vidro em numerosas aplicações (comummente designado por vidro acrílico). A síntese do poli(metacracrilato de metilo) pode ser efectuada por polimerização na massa, utilizando como iniciador o peróxido de benzoílo (Esquema 2). Esta técnica de polimerização é muito simples de implementar do ponto de vista experimental, uma vez que não exige equipamento especial. Pode ser efectuada num tubo de ensaio ou num erlenmeyer, utilizando um banho de água ou de parafina para proceder ao aquecimento. Esta técnica consiste em dissolver o iniciador no monómero e aquecer até que a mistura se torne sólida, sem a utilização de qualquer solvente ou aditivo. Apresenta como principal desvantagem o facto de ser difícil de controlar, principalmente quando a reacção é exotérmica. ${ }^{6}$

O polímero preparado pode ser caracterizado através da determinação do seu peso molecular médio viscosimétrico $(\bar{M} v)$, utilizando um viscosímetro de Ubbelohde ou de Cannon-Fenske que existem na maioria dos laboratórios de polímeros. O $\bar{M} v$ é determinado através da equação de Mark-Houwink: $[\eta]=\mathrm{K}(\bar{M} v)^{\alpha}$, em que [ๆ] é a viscosidade intrínseca e $\mathrm{K}$ e $\alpha$ duas constantes que se encontram tabeladas para este polímero, ${ }^{7}$ que dependem da temperatura e do solvente. A viscosidade intrínseca é obtida graficamente, através da extrapolação para zero da recta que relaciona a viscosidade relativa $\left[\mathrm{t} /\left(\mathrm{t}-\mathrm{t}_{0}\right)\right] / c \mathrm{com}$ a concentração $(c) .{ }^{8}$ Neste trabalho o solvente utilizado foi acetona, pelo que $\mathrm{K}=5,5 \times 10^{-3} \mathrm{e} \alpha=0,73$, a $20^{\circ} \mathrm{C}$. Para o polímero preparado nas condições descritas na parte experimental obteve-se um peso molecular médio viscosimétrico da ordem dos $60.000 \mathrm{~g} / \mathrm{mol}$.

Os filmes de polímero contendo cada um dos fotoprotetores são preparados por dissolução dos produtos de condensação aldólica numa solução do polímero. Por deposição destas misturas em placas de vidro e após evaporação do solvente à temperatura ambiente, obtêm-se filmes que são utilizados para efectuar os espectros de UV-Visível.

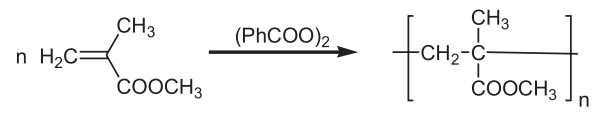

Mecanismo da polimerização

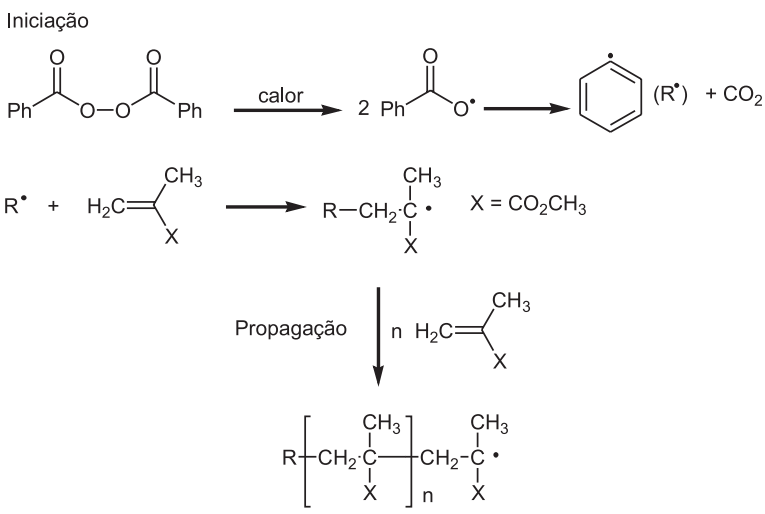

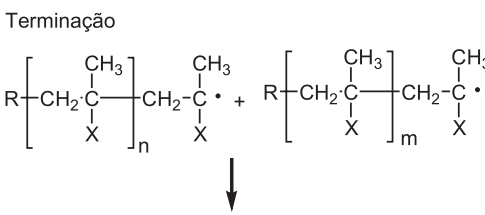

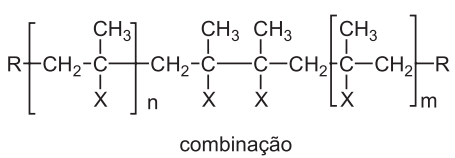

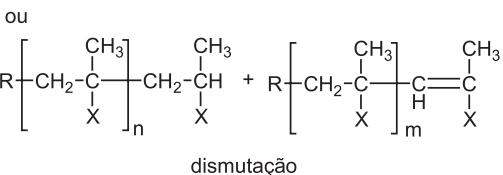

Esquema 2.

A transmitância $(\mathrm{T})$ é a fracção de luz incidente $\left(\mathrm{I}_{0}\right)$ que para um determinado comprimento de onda passa através de uma amostra $(\mathrm{T}=\mathrm{I} / \mathrm{I} 0$ ). A transmitância está relacionada com a absorbância (quantidade de luz que é absorvida por uma amostra em cada cumprimento de onda da radiação incidente) através da equação $\mathrm{A}=-\log _{10} \mathrm{~T}$. A medida experimental da transmitância pode ser realizada directamente no espectrofotómetro de UV-VIS. Para os polímeros preparados neste trabalho obtiveram-se os espectros de transmitânica de UV-VIS que se mostram na Figura 1.

Segundo a norma ABNT NBR 15.111:2004 os óculos de sol podem classificar-se em função dos limites de transmitância (Tabela 1). Os filmes obtidos neste trabalho classificam-se na categoria 4 quanto à protecção contra a radiação UVB e UVA. A única excepção é o filme $\mathrm{B}$, filme com o derivado do benzaldeído, que se classifica na categoria 2 na protecção contra irradiação UVA. Qualquer um dos filmes preparados é um bom exemplo de incorporação de fotoprotetores em polímeros sólidos para a obtenção de lentes de óculos de sol que cumprem a normativa vigente quanto a protecção exigida contra a radiação ultravioleta.

Os alunos podem ainda medir a transmitância dos seus próprios óculos de sol e conferir a sua adequação às normas existentes quanto a protecção da radiação ultravioleta.

\section{PARTE EXPERIMENTAL}

Os aldeídos utilizados, benzaldeído, anisaldeído e cinamaldeído 


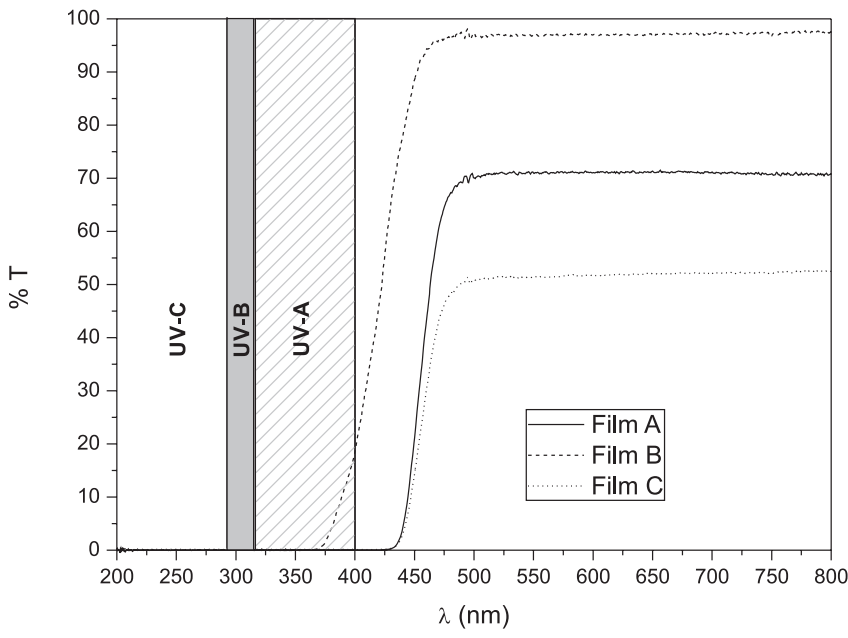

Figura 1. Espectros de UV-VIS dos filmes obtidos. Filme B: filme com o produto da condensação aldólica do benzaldeído. Filme A: filme com o produto da condensação aldólica do anisaldeído. Filme C: filme com o produto da condensação aldólica do cinamaldeído

Tabela 1. Categorias de óculos de sol em função de limites de transmitância.

\begin{tabular}{lcc}
\hline \multirow{2}{*}{ Categoria } & \multicolumn{2}{c}{ Radiação Ultravioleta } \\
& \% T UVB tolerada & \% T UVA tolerada \\
\hline 0 & $8,0-10,0$ & $80,0-100,0$ \\
1 & $4,3-8,0$ & $43,0-80,0$ \\
2 & $1,8-4,3$ & $18,0-43,0$ \\
3 & $0,8-1,8$ & $4,0-9,0$ \\
4 & $0,3-0,8$ & $1,5-4,0$ \\
\hline
\end{tabular}

(comercializados pela Merck), apresentam um grau de pureza $>97 \%$. A acetona utilizada é p.a. (comercializada pela Fluka). O peróxido de benzoílo ( $25 \%$ de água) e o metacrilato de metilo (pureza > 99\%) são comercializados pela Merck. Todos os outros reagentes e solventes utilizados apresentam pureza analítica.

Os pontos de fusão dos produtos de condensação aldólica foram determinados usando um Electrothermal Melting Point Apparatus (os valores não são corrigidos). Os espectros de infravermelho foram efectuados num espectrofotómetro Thermo Scientific Nicolet 6700 FTIR e os espectros de ressonância magnética nuclear de ${ }^{1} \mathrm{H}$ foram efectuados num espectrómetro Bruker Avance III $400 \mathrm{MHz}$ usando TMS como padrão interno. O espectrofotómetro de UV-Vis utilizado foi um Shimadzu UV-2100.

\section{Preparação dos produtos de condensação aldólica}

Colocar $4 \mathrm{~mL}$ de cada um dos aldeídos e $1 \mathrm{~mL}$ de acetona em 20 $\mathrm{mL}$ de etanol num balão de fundo redondo de $100 \mathrm{~mL}$. A esta solução adicionar $15 \mathrm{~mL}$ de hidróxido de sódio aquoso a $2 \mathrm{M}$. Com um condensador de ar no balão, manter a mistura em banho-maria a 30-35 ${ }^{\circ} \mathrm{C}$ durante 10-15 min, agitando vigorosamente. Terminado o aquecimento, deixar repousar durante $30 \mathrm{~min}$, agitando ocasionalmente.

O produto cristaliza por arrefecimento em água gelada. Filtrar os cristais com sucção, lavar com um pouco de água gelada e depois com um pouco de uma solução gelada de ácido acético a $4 \%$ em etanol. Os produtos podem ser recristalizados em etanol a quente. Obtiveram-se rendimentos médios superiores a $80 \%$, para qualquer dos produtos.

Os produtos podem ser caracterizados através da determinação dos pontos de fusão e por espectroscopia de IV e RMN.

$(1 E, 4 E)$-1,5-difenilpenta-1,4-dien-3-ona: $\mathrm{RMN}^{1} \mathrm{H}(400 \mathrm{MHz}$, $\left.\mathrm{CDCl}_{3}\right), \delta$ (ppm): 7,74(d, 2H, $\left.J=15,8 \mathrm{~Hz}\right) ; 7,64-7,61(\mathrm{~m}, 4 \mathrm{H}) ; 7,43-$ 7,41(m, 6H); 7,09(d, 2H, $J=15,8 \mathrm{~Hz}) . \mathrm{IV}(\mathrm{KBr}) \mathrm{cm}^{-1}: 1650,1591$, $1345,1195,984,762,696$. p.f. $\left({ }^{\circ} \mathrm{C}\right): 112-113^{\circ} \mathrm{C}$ (teórico $113{ }^{\circ} \mathrm{C}$ ).$^{9}$

(1E,4E)-1,5-bis(4-metoxifenil)-penta-1,4-dien-3-ona: $\mathrm{RMN}^{-1} \mathrm{H}$ (400 MHz, $\left.\mathrm{CDCl}_{3}\right), \delta(\mathrm{ppm}): 7,70(\mathrm{~d}, 2 \mathrm{H}, J=15,6 \mathrm{~Hz}) ; 7,57(\mathrm{~d}, 4 \mathrm{H}, J$ $=8,8 \mathrm{~Hz}) ; 6,96(\mathrm{~d}, 2 \mathrm{H}, J=15,6 \mathrm{~Hz}) ; 6,93(\mathrm{~d}, 4 \mathrm{H}, J=8,8 \mathrm{~Hz}) ; 3,86(\mathrm{~s}$, $6 \mathrm{H})$. IV(KBr) $\mathrm{cm}^{-1}: 1597,1510,1240,1177,1030,981,836$. p.f. $\left({ }^{\circ} \mathrm{C}\right): 128-129^{\circ} \mathrm{C}$ (teórico $129-130{ }^{\circ} \mathrm{C}$ ). ${ }^{9}$

(1E,3E,6E,8E)-1,9-difenilnona-1,3,6,8-tetraen-5-ona: RMN${ }^{1} \mathrm{H}\left(400 \mathrm{MHz}, \mathrm{CDCl}_{3}\right), \delta(\mathrm{ppm}): 7,50-7,45(\mathrm{~m}, 6 \mathrm{H}) ; 7,40-7,30(\mathrm{~m}$, $6 \mathrm{H}) ; 7,02-7,92(\mathrm{~m}, 4 \mathrm{H}) ; 6,57(\mathrm{~d}, 2 \mathrm{H}, J=15,2 \mathrm{~Hz}) . \mathrm{IV}(\mathrm{KBr}) \mathrm{cm}^{-1}$ : $1644,1619,1578,1247,1003,753$, 693. p.f. $\left({ }^{\circ} \mathrm{C}\right): 140-141{ }^{\circ} \mathrm{C}$ (teórico $\left.144^{\circ} \mathrm{C}\right) .^{9}$

\section{Preparação do PMMA}

\section{Remoção do inibidor do metacrilato de metilo}

Extrair $30 \mathrm{~mL}$ de metacrilato de metilo com $15 \mathrm{~mL}$ de uma solução aquosa contendo $2 \mathrm{~g}$ de $\mathrm{NaOH}$ e $10 \mathrm{~g}$ de $\mathrm{NaCl}$ em $100 \mathrm{~mL}$. Desprezar a camada aquosa e repetir a extracção mais duas vezes. Lavar o monómero com várias porções de $20 \mathrm{~mL}$ de água até que esta não apresente reacção alcalina (com papel indicador medir o $\mathrm{pH}$ da fase aquosa utilizada na lavagem do monómero). Secar a fase orgânica com cloreto de cálcio anidro. Filtrar.

\section{Preparação do poli(metacrilato de metilo) por polimerização na massa}

Num tubo de ensaio colocar $5 \mathrm{~mL}$ de monómero sem inibidor e adicionar $100 \mathrm{mg}$ de peróxido de benzoílo. Colocar a reagir num banho a $80{ }^{\circ} \mathrm{C}$ durante $30 \mathrm{~min}$. Terminada a reacção, dissolver os polímeros formados em acetona e reprecipitar por adição de água. Filtrar e secar em estufa a $30-40{ }^{\circ} \mathrm{C}$.

\section{Preparação das amostras para viscosimetria}

Se se utilizar um viscosímetro de Cannon-Fenske preparar pelo menos quatro soluções de polímero de concentrações entre $1 \times 10^{-3} \mathrm{a}$ $1 \times 10^{-2} \mathrm{~g} / \mathrm{mL}$, em acetona. Caso se utilize um viscosímetro de Ubbelohde preparar apenas uma solução de concentração 1 x $10^{-2} \mathrm{~g} / \mathrm{mL}$, em acetona (as diluições são, neste caso, feitas no próprio viscosímetro).

\section{Determinação do peso molecular das amostras por viscosimetria}

Medir no viscosímetro o tempo de escoamento do solvente (acetona), utilizando um banho termostático para manter a temperatura a $20 \pm 0,1^{\circ} \mathrm{C}$. Para cada uma das soluções preparadas é medido no viscosímetro o tempo de escoamento da solução. A viscosidade espe-

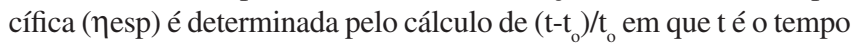
de escoamento de cada uma das soluções preparadas e to o tempo de

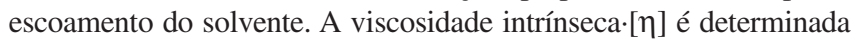
através da extrapolação para zero do gráfico da viscosidade reduzida (クesp/c) versus concentração. Através da equação de Mark-Houwink, determinar o valor do peso molecular de cada uma das amostras, sabendo que $\mathrm{K}=5,5 \times 10^{-3} \mathrm{~mL} / \mathrm{g}$ e $\alpha=0,73$, em acetona a $20^{\circ} \mathrm{C}$.

\section{Preparação dos filmes com os fotoprotetores imobilizados}

Dissolver $1 \mathrm{~g}$ de polímero em $10 \mathrm{~mL}$ de acetona (pode demorar um pouco até que o polímero dissolva completamente). Pesar $10 \mathrm{mg}$ de cada um dos produtos de condensação aldólica para frascos de amostra. A cada frasco adicionar $1 \mathrm{~mL}$ da solução de polímero preparada. Agitar para dissolver os compostos. Depositar as misturas sobre placas de vidro, de preferência numa estufa a 
cerca de $30^{\circ} \mathrm{C}$. Deixar secar completamente. Remover os filmes das placas (podem ser mergulhados em água para serem mais facilmente retirados). Preparar também um filme só de polímero para efeitos comparativos.

\section{Análise dos filmes por UV-Visível}

Usar um espectrofotómetro de UV-Vis para analisar os vários filmes, utilizando ar como branco e colocando os filmes no porta-células do espectrofotómetro (que podem ser colados ao porta-células com fita adesiva). Verificar qual a eficácia dos fotoprotetores em relação aos UVA (320-400 nm) e UVB (290-320).

\section{PLANEJAMENTO PARA O PROFESSOR}

Para a síntese dos compostos de condensação aldólica são necessários os seguintes reagentes e solventes por aluno: benzaldeído (4 mL), anisaldeído (4 mL), cinamaldeído (4 mL), acetona (3 mL), $120 \mathrm{~mL}$ de etanol, $45 \mathrm{~mL}$ de $\mathrm{NaOH}$ 2M, $30 \mathrm{~mL}$ de ácido acético $4 \%$ em etanol. Material de vidro necessário para a execução: 3 balões de fundo redondo de $100 \mathrm{~mL}, 4$ pipetas graduadas de $5 \mathrm{~mL}$, duas provetas de $50 \mathrm{~mL}, 3$ condensadores, placa de agitação e aquecimento, magnetes, banho de água, funil de Buchner, kitasato e 3 erlenmeyers de $100 \mathrm{~mL}$. Tempo necessário para a execução desta tarefa: $3 \mathrm{~h}$.

Para a síntese do polímero são necessários os seguintes reagentes e solventes por aluno: $30 \mathrm{~mL}$ de monómero, $2 \mathrm{~g}$ de $\mathrm{NaOH}, 10 \mathrm{~g}$ de $\mathrm{NaCl}, 100 \mathrm{mg}$ de peróxido de benzoílo, $50 \mathrm{~mL}$ de acetona, papel indicador, cloreto de cálcio de anidro, papel de filtro, funil de vidro, 2 erlenmeyer de $100 \mathrm{~mL}$, termómetro, tubo de ensaio, funil de placa porosa, kitasato. Tempo necessário para a execução desta tarefa: $2 \mathrm{~h}$.

Para as determinações de viscosimetria são necessários 200 $\mathrm{mL}$ de acetona, 4 balões de diluição de $50 \mathrm{~mL}$, um viscosímetro, um cronómetro e um banho termostático. Tempo necessário para a execução desta tarefa: $2 \mathrm{~h}$.

Para a preparação e análise dos filmes são necessários $1 \mathrm{~g}$ de polímero, $10 \mathrm{~mL}$ de acetona, $10 \mathrm{mg}$ de cada um dos produtos de condensação aldólica, um erlenmeyer de $25 \mathrm{~mL}$, um magnete, 3 frascos de amostra, uma pipeta graduada de $1 \mathrm{~mL}, 3$ placas de vidro (podem ser lamelas), espectrofotómetro de UV-vis. Tempo necessário para a execução desta tarefa: $1 \mathrm{~h}$.

\section{MATERIAL SUPLEMENTAR}

Estão disponíveis gratuitamente em http://quimicanova.sbq.org.br os espectros de IV e RMN de ${ }^{1} \mathrm{H}$ dos produtos de condensação aldólica.

\section{AGRADECIMENTOS}

Os espectros de NMR foram obtidos no Laboratório de Ressonância Magnética Nuclear do Centro de Química de Coimbra (www. nmrccc.uc.pt), Universidade de Coimbra, financiado por REEQ/481/ QUI/2006 da FCT, POCI-2010 e FEDER, Portugal.

\section{REFERÊNCIAS}

1. Poon, T.; McIntyre, J. P.; Eller, C. F.; Eller, L. R.; Jones, K. M.; Masselo, W.; Norris, C. M.; Oelrich, J. A.; Pluim, T. A.; Dorigo, D. J.; Davis, M. A.; Davis, M. A.; Izumi, H. K.; Kelley, K. H.; Melamed, M. L.; Poplawski, S. E.; St. Clair, J. M.; Stokes, M. P.; Wheeler, W. C.; Wilkes, E. E.; J. Chem. Educ. 1999, 76, 1523.

2. Guaratini, T.; Callejon, D. R.; Pires, D. C.; Lopes, J. N. C.; Lima, L. M.; Giannella Neto, D.; Sustovich, C.; Lopes, N. P.; Quim. Nova 2009, 32, 717.

3. Walters, C.; Keeney, A.; Wigal, C. T.; Johnston, C. R.; Cornelius, R. D.; J. Chem. Educ. 1997, 74, 99.

4. Juang, L.-J.; Wang, B.-S.; Tai, H.-M.; Hung, W.-J.; Huang, M.-H.; J. Food Drug Anal. 2008, 16, 22.

5. Handayani, S.; Arty, I. S.; J. Physical Sci. 2008, 19, 61.

6. Stevens, M. P.; Polymer Chemistry, an Introduction, $3^{\text {rd }}$ ed., Oxford University Press: New York, 1999.

7. Brandrup, J.; Immergut, E. H.; Polymer Handbook, $2^{\text {nd }}$ ed., John Wiley and Sons, Inc: New York, 1975.

8. Mathias, L. J.; J. Chem. Educ. 1983, 60, 422.

9. Mohrig, J. R.; Morrill, T. C.; Hammond, C. N.; Neckers, D. C.; Experimental Organic Chemistry, W. H. Freeman and Company: New York, 1998. 
SÍNTESE DE FOTOPROTETORES E SUA IMOBILIZAÇÃO EM POLI(METACRILATO DE METILO): UM PROJETO INTEGRADO DE QUÍMICA ORGÂNICA, QUÍMICA DE POLÍMEROS E FOTOQUÍMICA

Dina Maria B. Murtinho*, Maria Elisa S. Serra e Marta Pineiro

Departamento de Química, Faculdade de Ciências e Tecnologia, Universidade de Coimbra, 3004-535 Coimbra - Portugal

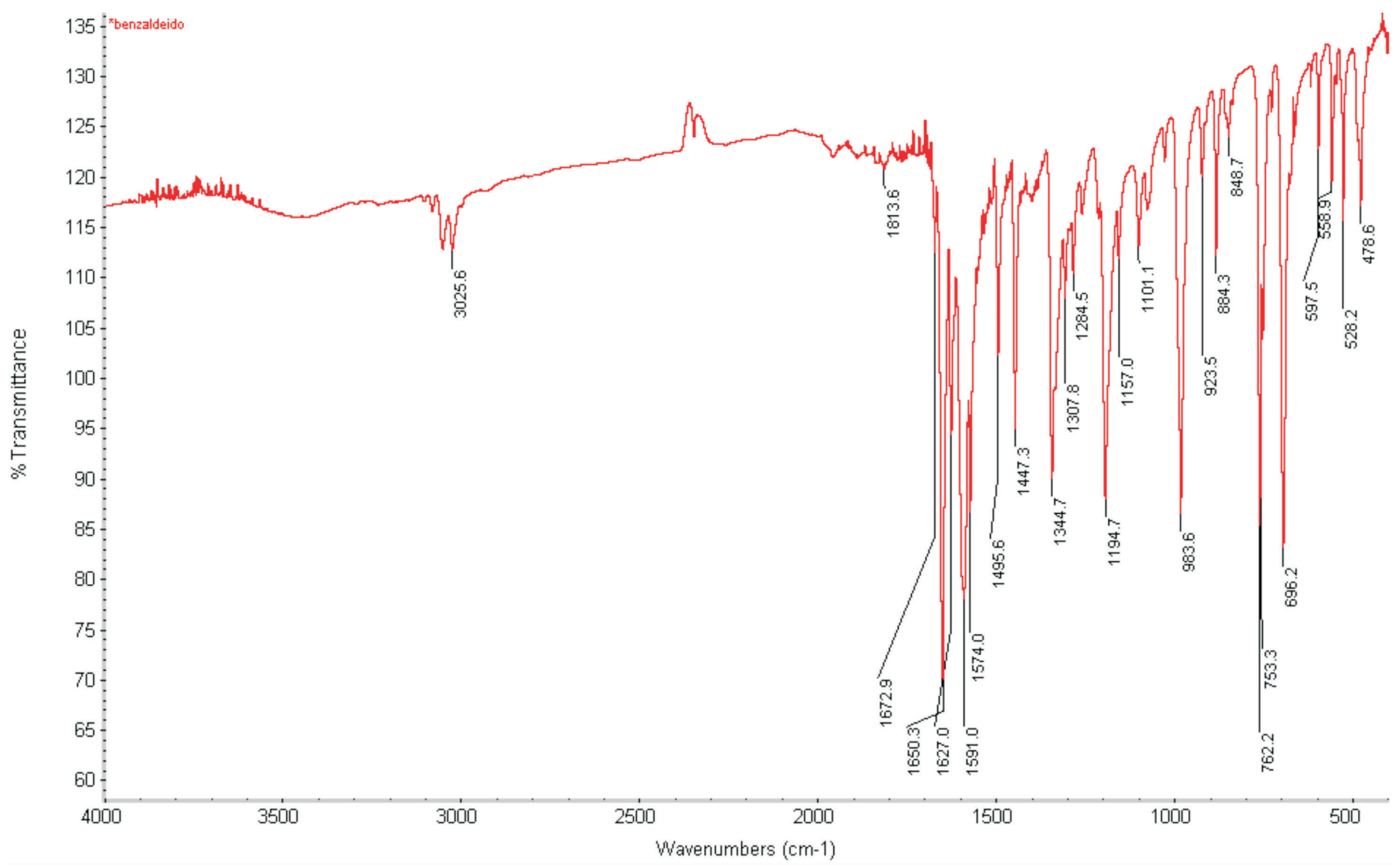

Figura 1S. Espectro de IV do produto de condensação da acetona com o benzaldeído 


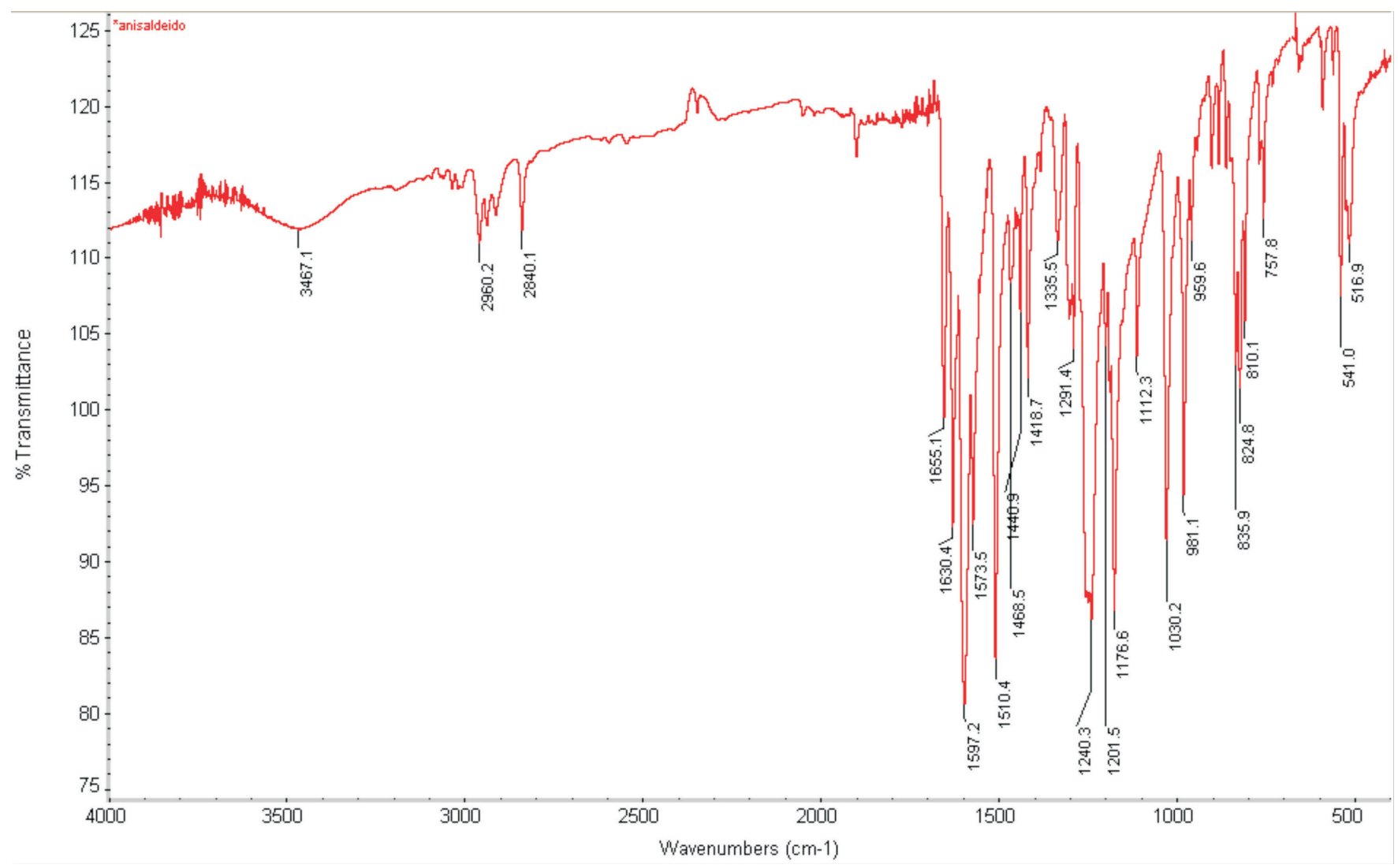

Figura 2S. Espectro de IV do produto de condensação da acetona com o anisaldeído

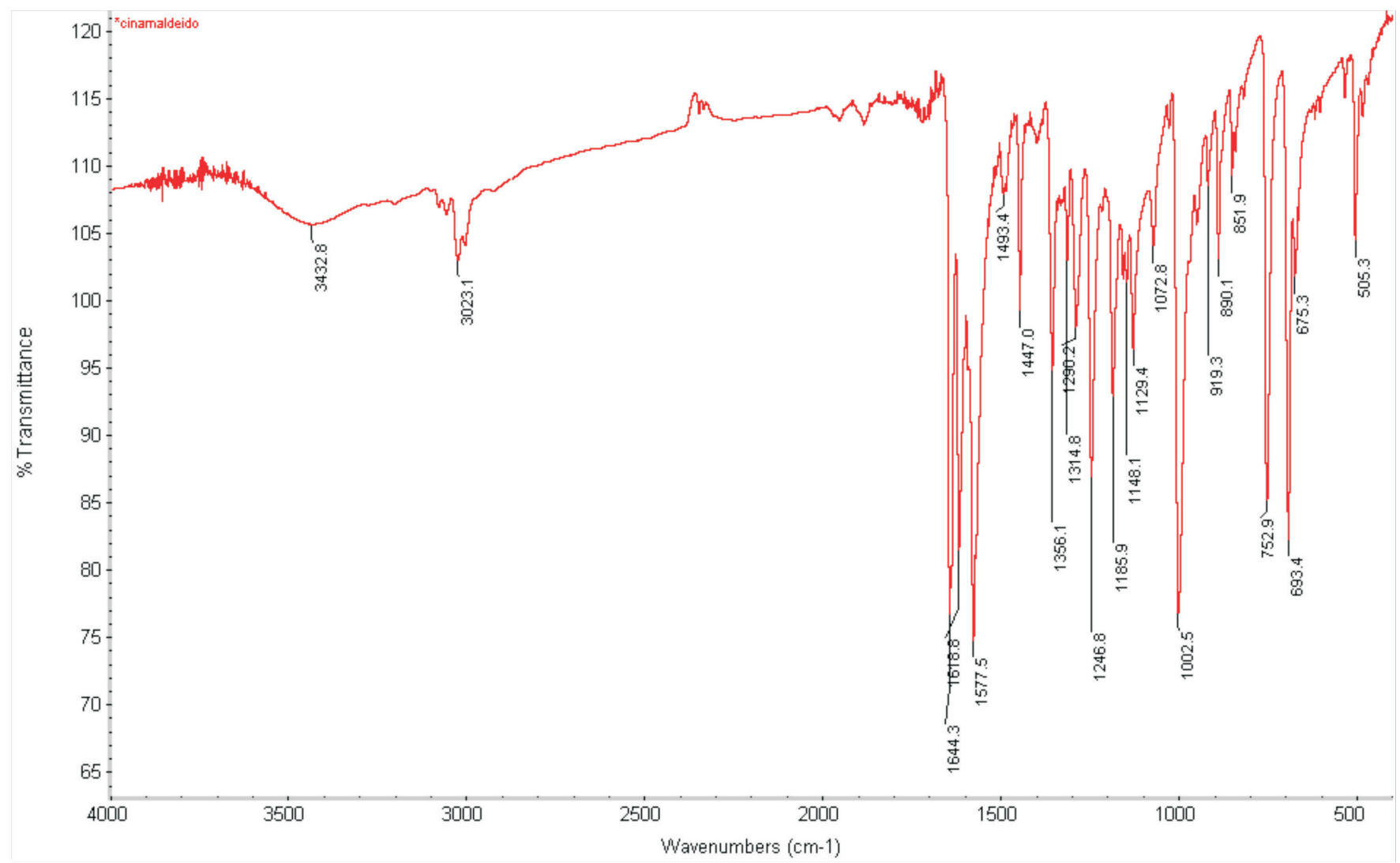

Figura 3S. Espectro de IV do produto de condensação da acetona com o cinamaldeído 


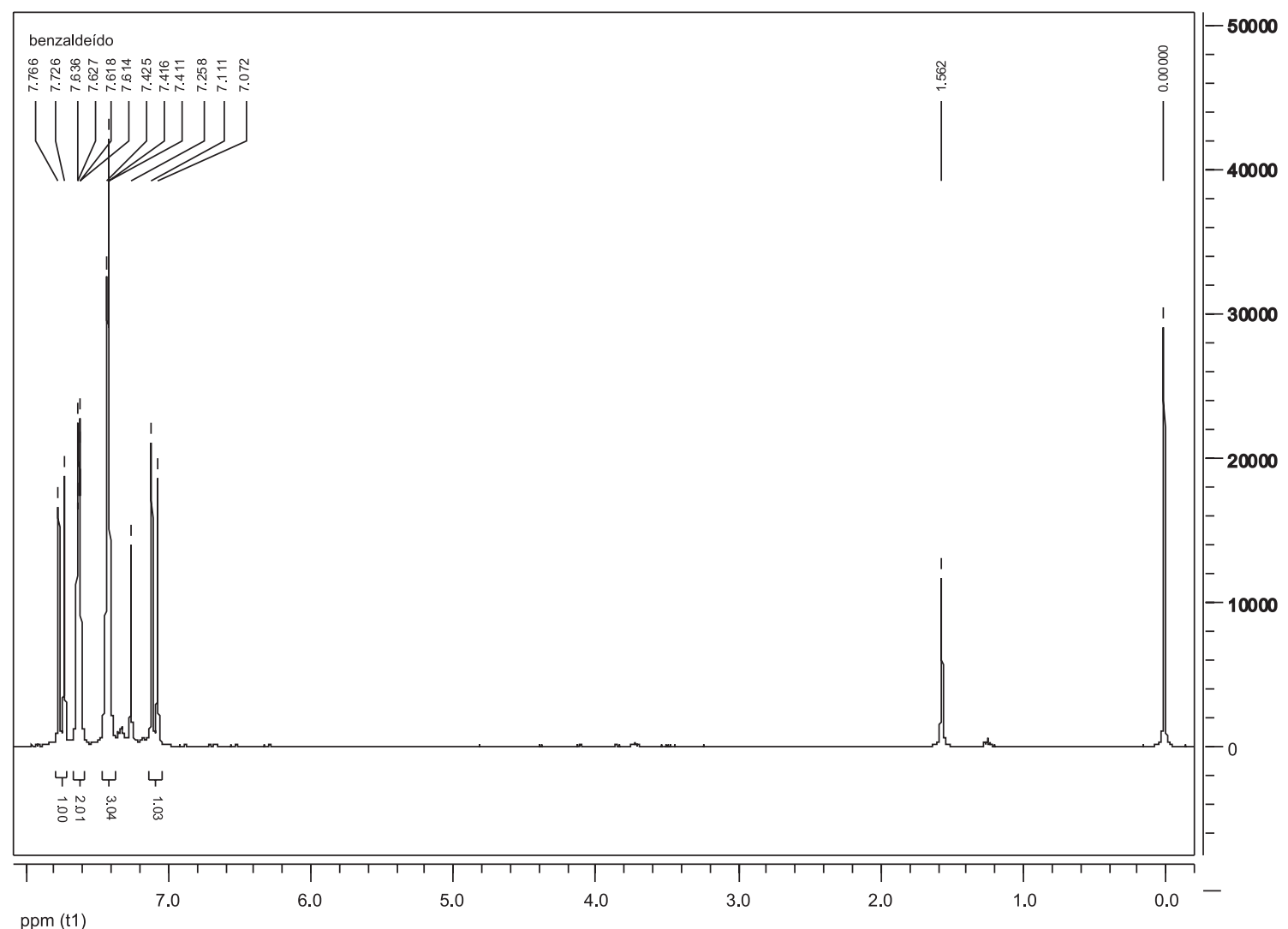

Figura 4S. Espectro de RMN de ${ }^{1} \mathrm{H}$ do produto de condensação da acetona com o benzaldeído

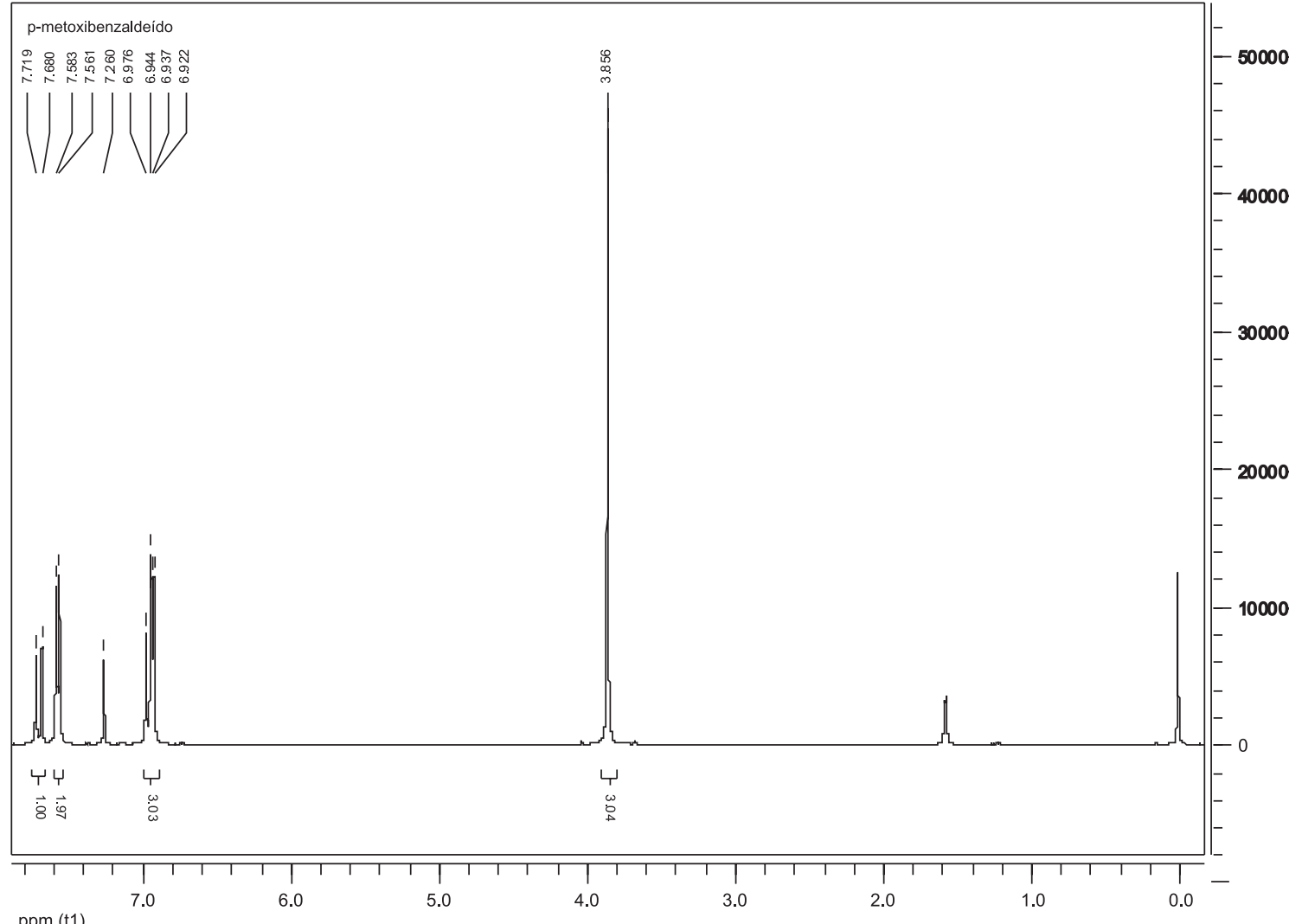

Figura 5S. Espectro de RMN de ${ }^{l} H$ do produto de condensação da acetona com o anisaldeído 


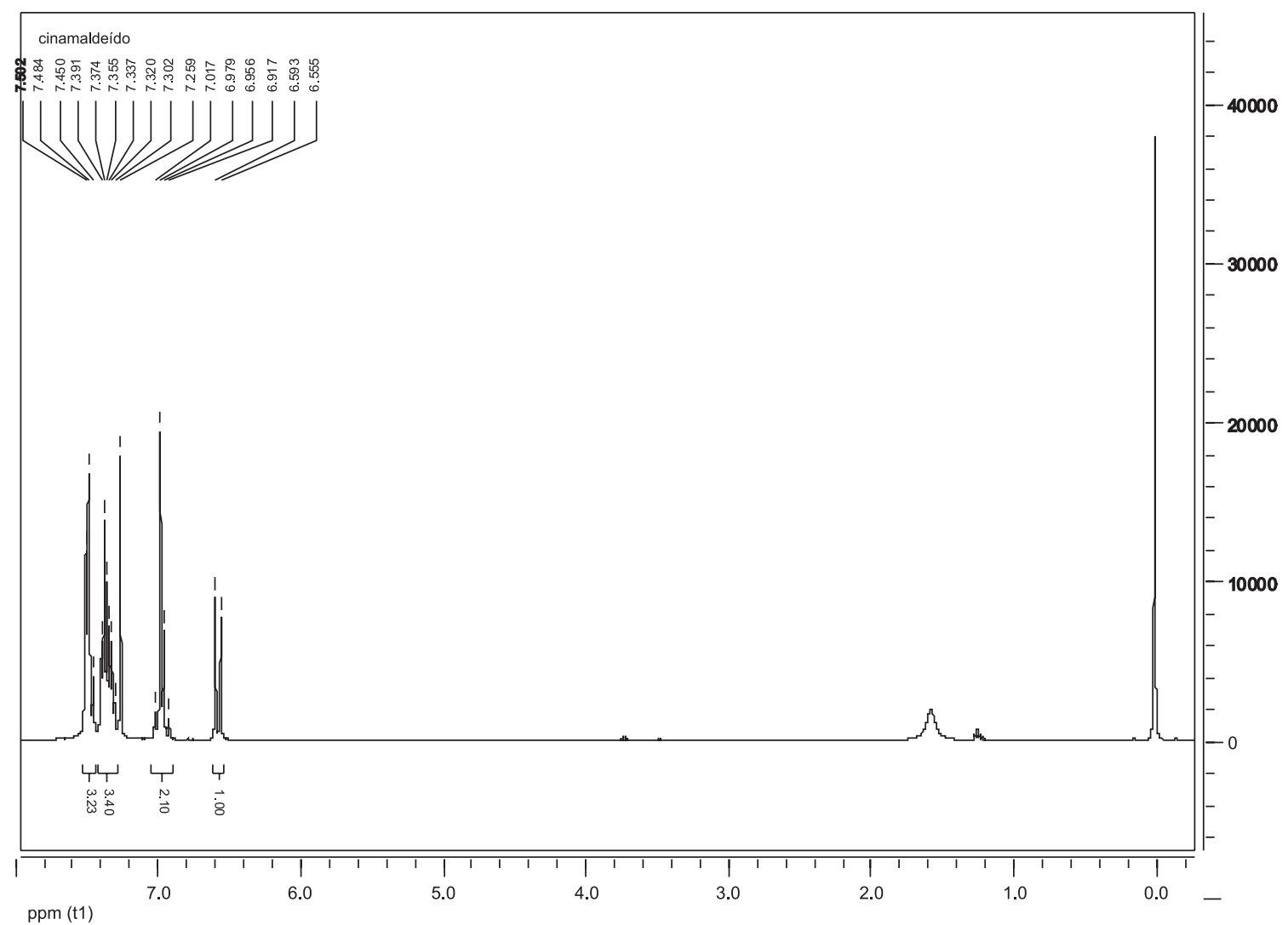

Figura 6S. Espectro de RMN de ${ }^{1} \mathrm{H}$ do produto de condensação da acetona com o cinamaldeído 